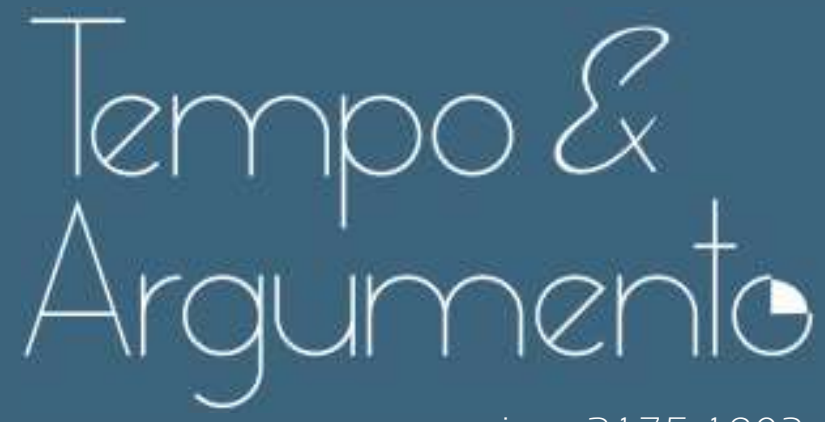

e-issn 2175-1803

\title{
La Historia del Tiempo Presente en México: desafíos y construcción de un campo
}

- Eugenia Allier Montaño

Doctora en Historia por la Ecole des Hautes Etudes en Sciences Sociales.

Investigadora titular del Instituto de Investigaciones Sociales de la

Universidad Nacional Autonoma México.

Ciudad de México - MÉXICO

iis.unam.mx/.../investigadores-de-sociedad-y-cultura/dra-allier-montano-eugenia/

eallier@gmail.com

(D) orcid.org/0000-0002-0992-8767

* César Iván Vilchis Ortega

Doctorando en Historia por la Universidad Nacional Autonoma México.

Ciudad de México - MÉXICO

cesar_vil_50@hotmail.com

(1) orcid.org/0000-0002-5811-9341

\section{Laura Andrea Ferro Higuera}

Doctoranda en Ciencias Políticas y Sociales por la Universidad Nacional

Autonoma México.

Ciudad de México - MÉXICO

unam.mx/.../ferro-higuera-laura-andrea/

laferroh@gmail.com

(D) orcid.org/0000-0003-4876-5355

Para citar este articulo (ABNT):

ALLIER MONTAÑO, Eugenia; VILCHIS ORTEGA, César Iván; FERRO HIGUERA, Laura Andrea. La Historia del Tiempo Presente en México: desafíos y construcción de un campo. Tempo e Argumento, Florianópolis, e0 101, 2021. Número especial.

dof http://dx.doi.org/10.5965/21751803ne2021 e0 101 


\title{
La Historia del Tiempo Presente en México: desafíos y construcción de un campo ${ }^{1}$
}

\begin{abstract}
Resumen
El interés por historizar el presente en México ha ido en aumento en los últimos años. Ello ha conllevado que la Historia del Tiempo Presente se haya convertido en una subdisciplina en consolidación que atraviesa un proceso de definición y de delineamiento propio. El objetivo del presente artículo es discutir y analizar la construcción y el estado actual de esta subdisciplina en el país: caracterizar la producción bibliográfica y desarrollar un pequeño balance acerca de sus áreas de interés, retos y posibles agendas de investigación. Para ello, además de definir lo que entendemos por Historia del Presente y estudiar las condiciones de emergencia en México, compartimos un trabajo de investigación cualitativo en torno a la revisión bibliográfica de índices mexicanos de revistas especializadas en Ciencias Sociales. Gracias a este trabajo, delineamos características del campo del presente histórico en el país, observando la consolidación e institucionalización paulatina de esta subdisciplina y señalando similitudes y diferencias en relación con el campo en Latinoamérica.
\end{abstract}

Palabras clave: historia del tiempo presente; México; historiografía; interdisciplina; institucionalización.

\section{History of the Present Time in Mexico: challenges and the building of a field}

\begin{abstract}
The interest in historicizing the present time in Mexico has been increasing in recent years. This means that History of the Present Time has become a subdiscipline in the consolidation that undergoes a process of definition and outline of its own. This article aims to discuss and analyze the building and the state-of-the-art of this subdiscipline in the country: to characterize the literature and take a quick stock of its areas of interest, challenges, and possible research agendas. To do this, in addition to defining what we understand as History of the Present and addressing the emergency conditions in Mexico, we share a qualitative research work on the literature review of Mexican indexes of specialized Social Science journals. Thanks to this work, we outline characteristics of the historical present as a field in the country, noticing the gradual consolidation and institutionalization of this subdiscipline and pointing out similarities and differences in relation to the field in Latin America.
\end{abstract}

Keywords: history of the present time; Mexico; historiography; interdiscipline; institutionalization. 
El interés por historizar el presente no es nuevo en México: varios de los principales representantes de la historiografía nacional escribieron y reflexionaron sobre su presente en distintos momentos. Lucas Alamán y José María Luis Mora sobre la Independencia, José María Vigil sobre la Reforma, Alfonso Taracena sobre la Revolución Mexicana, por citar algunos ejemplos. Mucho más cercanos a nosotros se encuentran los aportes de Lorenzo Meyer o Enrique Krauze, dos de los historiadores de mayor impacto mediático de las últimas décadas.

Sin embargo, la existencia de estos casos no significa que, en México, la Historia del Tiempo Presente sea un campo desarrollado como tal desde hace tiempo, como ocurre en algunos países de Europa y América Latina. Como trataremos de sostener en estas páginas, en el caso mexicano se trata más bien de una subdisciplina en desarrollo y consolidación, pues en los últimos años el interés por historizar el presente histórico ha ido en aumento en libros, artículos de revistas especializadas, así como tesis de licenciatura, maestría y doctorado. Sobre todo, ha surgido el interés por formar un campo compartido por múltiples historiadores. Ello puede observarse también en la organización de seminarios, congresos y coloquios: un indicio más de que este campo está en vías de construcción y expansión.

Abordar esta temática no es tarea sencilla. Cuando un campo historiográfico está en formación, el balance presenta dificultades. En el caso mexicano, se trata de un campo que, en la tercera década del siglo XXI, atraviesa un proceso de definición y de delineamiento propio. Por ello, el objetivo de este artículo es discutir y analizar la construcción y el estado actual de esta subdisciplina en México: caracterizar la producción bibliográfica y desarrollar un pequeño balance acerca de sus áreas de interés, retos y posibles agendas de investigación. Para ello, hemos dividido el texto en tres apartados. En el primero, damos una rápida definición de lo que entendemos por Historia del Presente. En el segundo, analizamos las condiciones de surgimiento de este campo historiográfico en México, diferenciando sus características con las existentes en otros países de América Latina. En el tercero, exponemos un trabajo de investigación realizado especialmente para este artículo con base en una búsqueda bibliográfica -artículos de revistas especializadas de Historia y Ciencias 
Sociales- para acercarnos a la evolución del campo en México. Por último, hacemos unas consideraciones mínimas sobre esta parcela historiográfica en el país.

\section{La Historia del Presente: orígenes y definición}

A principios de los años 1970, se acuñó en Francia el término historia del tiempo presente, dando inicio a un fuerte crecimiento de este campo historiográfico que, igual que otras subdisciplinas surgidas en los años 1970, tuvo una triple causalidad. En primer lugar, diversos procesos sociales, como las demandas de grupos minoritarios o subalternos, el peso de pasados-presentes violentos y dolorosos, como el Holocausto. En segundo lugar, la crisis de las Ciencias Sociales y de la Historia, en particular. Y, en tercer lugar, el surgimiento de otras historias paralelas (DELACROIX, 2007).

Pese a la importancia creciente de este campo historiográfico, son pocos los trabajos teóricos que le son dedicados. Entre ellos, conviene destacar: Écrire l'histoire du temps présent, trabajo colectivo publicado en 1993 por el Instituto de Historia del Tiempo Presente, en Francia; Historia del tiempo presente, de Josefina Cuesta Bustillo (1993); History of the present, de Timothy Garton Ash (1999); La historia vivida, de Julio Aróstegui (2004); La historia del tiempo presente: historiografía, problemas y método, de Hugo Fazio (2010); La dernière catastrophe. L'histoire, le présent, le contemporain, de Henry Rousso (2013); y En la cresta de la ola. Debates y definiciones en torno a la historia del tiempo presente, coordinado por Eugenia Allier Montaño, César Iván Vilchis Ortega y Camilo Vicente Ovalle (2020).

Si bien existen distintas caracterizaciones, hemos propuesto entender esta forma de hacer historia a partir de seis rasgos distintivos. En primer lugar, que su objeto central es el estudio del presente. En segundo término, que el presente está determinado por la existencia de las generaciones que vivieron un acontecimiento, es decir, la existencia de testigos y actores implica que ellos podrían dar su testimonio a los historiadores, por lo que la presencia de una memoria colectiva del pasado es determinante para este campo historiográfico. Ligada a esta cuestión aparece la tercera característica: la coetaneidad entre la 
experiencia vivida por el historiador y el acontecimiento del que se ocupa, particularmente por su vínculo con las generaciones que experimentaron un momento histórico. En cuarto lugar, estaría la perspectiva multidisciplinaria del campo. En quinto lugar, las demandas sociales por historizar el presente, particularmente temáticas de violencia, trauma y dolor -mismas que aparentemente se han convertido en los ejes de esta parcela historiográfica, aunque ello no implica que los temas se limiten a ellos y no puedan ser otros-. Por último, las tensiones y complicidades entre historiadores y testigos (ALLIER MONTAÑO, 2018; ALLIER MONTAÑO; VILCHIS ORTEGA; VICENTE OVALLE, 2020).

Imposible desarrollar todos esos aspectos en estas páginas. Aunque si quisiéramos explayarnos en la cuestión de la multidisciplinariedad. Hace tiempo que las Ciencias Sociales y las humanidades se encuentran en zonas grises respecto a su delimitación disciplinar. Para la Historia, Peter Burke (2003) ha señalado que en ocasiones es más fácil para un historiador de la economía vincularse con economistas que con historiadores. Y así en cada subdisciplina. Pero todo ello es aún más evidente en la Historia del Presente: una subdisciplina fuertemente multidisciplinaria, que se relaciona con, y toma prestadas metodologías y teorías de la sociología, la antropología, la ciencia política, el psicoanálisis, la filosofía. Una de las particularidades del campo es, pues, el diálogo e intercambio intenso y novedoso con otras disciplinas que estudian temas cercanos.

La Historia del Tiempo Presente es una forma de acercamiento histórico a realidades humanas de las cuales aún vive al menos 1 de las 3 generaciones que conocieron de manera directa los hechos. Frente a ello, muchos pueden preguntar qué la diferencia entonces de disciplinas como la Sociología: no es el tema, sino la forma de abordarlo. Retomando a Marc Bloch (1997), podemos decir que la Historia siempre historiza, es decir analiza transformaciones y continuidades de los seres humanos en el tiempo.

Se puede observar que existe un vínculo estrecho entre el mundo observado y el mundo pensado, entre la realidad y las categorías utilizadas. Pero más allá de la influencia social y política, es importante revisar cuestiones epistemológicas que nos permitan justificar el uso del término historia del tiempo 
presente sobre otras denominaciones existentes. Este concepto admite que nos descentremos de la periodización: no se trata de un momento/periodo de la historia, sino de una forma de hacer historia. Por eso el alejamiento con la noción de historia reciente e historia contemporánea. Lo mismo frente a historia inmediata: la Historia del Presente no se interesa por la inmediatez, por ese momento que ya se ha ido cuando lo queremos capturar. Esta subdisciplina enfocada en el presente nos permite pensar en un tiempo en el que los procesos son considerados como actuales, social y subjetivamente. Una historia de la coetaneidad que permite el acercamiento a aquellos que vivieron la historia y que son nuestros contemporáneos.

El trabajo del historiador del presente si bien conlleva un riesgo ético y político (ALLIER MONTAÑO, 2020), al mismo tiempo es un área de oportunidad. Esta labor tiene el potencial de complejizar los discursos políticos y culturales sobre temas contemporáneos urgentes: la violencia, la guerra, el trabajo, las movilizaciones sociales, los desastres naturales, la conmemoración y la memoralización. En México: el narcotráfico, las personas desaparecidas y los feminicidios. Además, es importante señalar la avidez de un público no especialista por escuchar historia sobre acontecimientos y procesos que lo tocan de cerca. Dato que se observa en la presión de las editoriales al solicitar a los especialistas colecciones sobre Historia del Presente (ROMANO; POTTER, 2012). Se trata de lectores interesados en leer historias que han afectado a su propia generación.

\section{Especificidades históricas de la Historia del Presente en México}

Si bien la Historia del Tiempo Presente tiene más de 40 años de institucionalizada en Francia y Alemania, en América Latina su difusión es más o menos reciente y su desarrollo muy desigual. En Argentina y Uruguay, la construcción del campo se inició hace unos 15 o 20 años, con la motivación del peso del pasado reciente en los debates públicos. Por ello, para muchos especialistas, la Historia del Presente es "hija del dolor" (FRANCO; LEVÍN, 2007), “hija de la última catástrofe nacional" (ROUSSO, 2013). Y, en buena medida, el surgimiento de este campo se ha debido a esos motivos en muchos de los países en que se ha instalado. 
México también ha conocido periodos de gran violencia política, de violencia de Estado. No obstante, el peso de ese pasado-presente en la arena pública no ha sido similar al de otros países de Latinoamérica, como Argentina, Chile y Uruguay (ALLIER MONTAÑO; CRENZEL, 2015). Seguramente ello ha afectado en el hecho de que tanto los estudios de la memoria como la Historia del Tiempo Presente hayan encontrado de forma más lenta su lugar en la academia histórica mexicana. Es sólo recientemente que se está comenzando a conformar un campo, y aunque en éste el peso de los estudios sobre violencia política -movimiento estudiantil de 1968, movimientos armados, Guerra Sucia-2 es muy importante, y convoca a una gran parte de los investigadores, esta subdisciplina se ha abierto a un abanico amplio de temáticas y de décadas. En ese sentido, consideramos que la impronta principal de la Historia del Presente en México tendría que ver con esos dos elementos: la periodización y las temáticas. No es un tema, no es un periodo, es una forma de hacer una historia que estudia el presente, que se está moviendo mientras se realiza, y que lo mismo estudia la violencia política que la ecología o la cultura.

Y ésa es probablemente una de las grandes diferencias de la Historia del Presente que se hace en México con otros campos existentes en América Latina, particularmente el Cono Sur: no se trata de un periodo -como en el caso de la historia reciente en Argentina, Chile y Uruguay-. Ello se debe a la propia historia política que se ha vivido en el país. En México no se puede hablar de una violencia política o de un periodo en el que se haya vivido la violencia política. Para este caso, es más justo hablar de distintos periodos de violencia (ALLIER MONTAÑO; VICENTE OVALLE; GRANADA, 2022). Comparando con los países del Cono Sur, en México no hubo una dictadura cívico-militar con un inicio y un fin; sin embargo, muchos autores han comenzado a cuestionar el hecho de que se viviera en una democracia formal, sugiriendo que se trató de un régimen autoritario de un tipo particular, caracterizado por el régimen de partido único -del Partido Revolucionario Institucional (PRI), que gobernó desde los años 1930 hasta 2000(MEYER, 2013; VICENTE OVALLE, 2019). Por otra parte, también se cuestiona el

\footnotetext{
2 En México, se le conoce como "Guerra Sucia” al periodo que transcurre entre la década de 1970 y la de 1980, que estuvo caracterizado por la represión sistemática a distintas agrupaciones políticas, notoriamente el movimiento armado. Si bien el término ha sido cuestionado por algunos investigadores, tampoco se ha logrado consenso en la utilización de otro concepto.
} 
que haya existido una transición a la democracia. Más aún: la violencia, política y criminal, no ha concluido: los años 1970, 1980, 1990 y aún el siglo XXI han visto la existencia de la violencia política en contra de los opositores políticos, legales e ilegales, así como el incremento en la violencia criminal.

En ese sentido, puede decirse que ha existido una violencia de Estado recurrente: el Estado mexicano se construyó como un Estado que no permitía la disidencia, de ningún tipo. Si el opositor no lograba ser cooptado, era asesinado. La violencia de Estado en México, a diferencia de otros países de la región, es de larga duración, incluso a pesar de que ha habido cambios de partido político en el gobierno nacional (MONTEMAYOR, 2010; AGUAYO, 2015; ALLIER MONTAÑO; VICENTE OVALLE; GRANADA, 2022).

Todo ello ha generado un caso complicado: es muy probable que se haya dificultado la exigencia de verdad, justicia y reparación debido a esta falta de inicio y fin de un régimen político determinado, así como la inexistencia de una transición a la democracia y la continuidad de la violencia política. Por tanto, la demanda por parte de organizaciones de derechos humanos y víctimas no ha sido tan audible como en otros países (AGUAYO, 2009; SOMUANO, 2010; ÁLVAREZ ICAZA, 2010; ALLIER MONTAÑO, 2021). Esta ha sido probablemente otra de las causas que ha dificultado el surgimiento de la Historia del Presente en el país.

El hecho de que en México el peso del pasado reciente no haya sido tan fuerte como en el Cono Sur, ha generado serias desventajas, pero también algunas ventajas. La desventaja más evidente es que el campo comenzó a conformarse tardíamente en comparación con otros países de la región. La ventaja de llegar tarde al campo internacional es que esta subdisciplina se está articulando de otra manera. Hace unos 5-10 años que se comenzaron a hacer trabajos históricos sobre la violencia política en el país: el movimiento estudiantil de 1968, los movimientos armados y la Guerra Sucia de los años 1970-1980. Pero como lo veremos en el siguiente apartado, la Historia del Presente en México se está abriendo también a otros campos que no han estado presentes en otros países: la cultura, la ecología, los nuevos medios de comunicación. Al no estar ligada a un periodo histórico, la Historia del Presente en el país puede ampliar su panorama a renovaciones metodológicas y temáticas importantes para el campo. 
Vale la pena referir una última característica histórico-política de México, que ha influido en la forma de configurar la Historia del Presente. Se trata de la cuestión de la transición a la democracia. $Y$ es que, al respecto, hay tantas interpretaciones como especialistas. Para algunos, el proceso democratizador habría comenzado en 1968, con las exigencias del movimiento estudiantil por el respeto a la Constitución, las libertades civiles y la democratización del sistema político (LOAEZA, 1993). Se trató de la primera vez que se exigía una democracia política y no sindical, como en el movimiento ferrocarrilero de 1958-1959 o en el movimiento médico de 1964. Para otros, habría que situar los orígenes de la transición en 1977 con la Reforma Política de José López Portillo, que reglamentó la vida de los partidos políticos y permitió la llegada de la izquierda legal a la Cámara de Diputados (CANSINO ORTIZ, 2000). Otros más consideran que las elecciones de 1988 marcaron el despertar de una movilización social que exigía la democratización del sistema político (LABASTIDA MARTÍN DEL CAMPO; LÓPEZ LEYVA, 2004). Para la mayoría, la transición se ubica en el año 2000, con el triunfo del Partido Acción Nacional (PAN) en las elecciones nacionales y su llegada al gobierno (SALAZAR, 2001) $)^{3}$.

Incluso si tomamos como punto de partida de la transición el cambio de partido del año 2000, quedan muchas dudas de que realmente se haya tratado de una transición a la democracia. Para muchos, fue un cambio de partido, pero no de régimen. De hecho, la complicidad entre los partidos políticos que salieron y los que entraron, PRI y PAN, fue tal que ha sido imposible lograr acceder a la justicia y la verdad respecto de los crímenes del pasado. Muestra de ello es el poco éxito que tuvo la Fiscalía Especial para Movimientos Sociales y Políticos del Pasado (FEMOSPP), creada por Vicente Fox a inicios de su mandato (AGUAYO; TREVIÑO, 2007).

\footnotetext{
3 José Woldenberg (2002) ofrece un análisis del porqué en México no hay consenso sobre el inicio y la duración de la transición. Para él, México logró alcanzar en las últimas 2 décadas del siglo XX un régimen político que representaba la pluralidad política, o sea, un régimen democrático según la idea moderna de democracia. Considera que la falta de consenso acerca del inicio y duración de la transición a la democracia en México se debe a interpretaciones diversas respecto a qué acontecimiento podría considerarse como el inicio de la transición. Por lo demás, aún queda la difícil discusión de si en México ya se ha realizado realmente la transición a la democracia.
} 
Uno de los puntos fundamentales de las transiciones a la democracia es que eventualmente se dan cambios en las estructuras gubernamentales: el sistema parlamentario, el sistema judicial, se van transformando, aunque lentamente. ¿Cómo podría obtenerse justicia si sigue siendo administrada por los mismos políticos y jueces que estaban a cargo cuando ocurrió la violencia política? El caso de México es paradójico: no hay transición efectiva, no hay finalización del régimen autoritario, no hay justicia penal y la violencia va en aumento.

Si partimos de que la transición a la democracia en México no ha sido efectiva, entendemos también otra de las causas de por qué la Historia del Tiempo Presente ha tardado tanto tiempo en instalarse en el país. Hace algunos años, Henry Rousso (2003) proponía, desde una reflexión que tomaba como eje el marco europeo, establecer un paralelo entre la existencia de un contexto democrático y el desarrollo institucional de la Historia del Tiempo Presente ${ }^{4}$.

Por supuesto no es la única razón. A ello hay que agregar otras cuestiones, como la forma en que se institucionalizó la profesión histórica en México, proceso del que resultó una academia que difícilmente ha aceptado el desarrollo de otras formas de hacer Historia -como la Historia Oral y la Teoría de la Historia-. Pero es posible que la falta de democratización del sistema político y del resto de la esfera pública hayan limitado, durante muchos años, las posibilidades para construir la Historia del Presente en México.

\section{La producción historiográfica en México}

Con la finalidad de realizar en primer acercamiento al estado actual del campo de la Historia del Presente en México, desarrollamos una búsqueda bibliográfica que tuvo como fuente principal la base de datos de la Red de Revistas Científicas de América Latina y el Caribe, España y Portugal (Redalyc) 5 .

\footnotetext{
${ }^{4}$ En efecto, la apertura de archivos es clave en la escritura de la Historia del Presente, aunque no definitiva. Benedetta Calandra (2015) Llevó a cabo un magnífico análisis sobre la no definitividad del acceso a los archivos en el caso de los desclasificados por Estados Unidos (EE. UU.) sobre América Latina. Para el caso mexicano sobre los archivos, ver Camilo Vicente Ovalle (2020).

${ }^{5}$ Alojado por la Universidad Autónoma del Estado de México (UAEM), este sistema de indización alberga más de 1.400 revistas, de 691 instituciones de 26 países, y toma en cuenta a las publicaciones que mantienen un modelo sin fines de lucro. Su elección tomó en consideración
} 
El proceso de búsqueda incluyó las siguientes palabras clave: historia del tiempo presente, historia del presente, historia inmediata, historia contemporánea e historia reciente. Todas ellas buscando concentrar el mayor número de registros que se relacionaran con el abordaje teórico, metodológico y empírico del tiempo presente de manera directa. Es importarte subrayar que, en Redalyc, la mayoría de las revistas disponibles para su consulta comienzan en el año 2000, por lo que nuestro rango de búsqueda fue a partir de ese año, y el periodo de estudio de los artículos consultados fue de la segunda mitad del siglo XX a la actualidad, considerando que es el rango a partir del cual aún vive 1 de las 3 generaciones que conocieron el periodo o un acontecimiento en particular.

\section{Revistas especializadas en Historia y Ciencias Sociales}

Compartimos con Javier Garciadiego que las revistas de Historia que se publican en México son:

[...] una perspectiva ideal para acercarse a la historiografía mexicana contemporánea, pues quedará mejor definido el proceso de profesionalización de la disciplina, su crecimiento institucional, los cambios en los temas de estudio y en las perspectivas de análisis, así como el creciente rigor de sus métodos y técnicas. (GARCIADIEGO, 2001, p. 222)

Además, creemos que son una ventana pertinente para evaluar el nacimiento de nuevas corrientes historiográficas en México. Las revistas son una forma de divulgación científica propia del presente que vivimos y que ha adquirido una preponderancia a la hora de divulgar científicamente el trabajo de los investigadores, tanto jóvenes como consolidados.

En efecto, un primer momento del trabajo de búsqueda consistió en identificar las revistas especializadas de Historia que con mayor frecuencia han publicado artículos sobre Historia del Presente. En la Tabla 1 observamos los nombres, el número de artículos que publicaron, su institución editora y el año de fundación. En la revisión es importante destacar no sólo los datos básicos de las revistas, sino también prestar atención a ciertos detalles que nos permitan 
vislumbrar el grado de institucionalización de la Historia del Presente en cada una de las instituciones que las editan. Por ejemplo, si el campo forma parte de sus líneas de investigación y/o programas de posgrado, si cuenta con algún departamento de investigación o seminario institucional sobre el tema.

Tabla 1 - Revistas científicas especializadas en Historia que publicaron trabajos sobre el presente histórico en México (2000-2021)

\begin{tabular}{|c|c|c|c|}
\hline Revista & Frecuencia & Institución & Año de fundación \\
\hline Historia Mexicana & 40 & El Colegio de México & 1951 \\
\hline Historia y Grafía & 38 & $\begin{array}{l}\text { Universidad } \\
\text { Iberoamericana }\end{array}$ & 1993 \\
\hline $\begin{array}{l}\text { Secuencia: Revista de } \\
\text { Historia y Ciencias } \\
\text { Sociales }\end{array}$ & 36 & Instituto Mora & 1985 \\
\hline Tzintzun & 21 & $\begin{array}{l}\text { Universidad } \\
\text { Michoacana }\end{array}$ & 1987 \\
\hline $\begin{array}{l}\text { Relaciones: Estudios } \\
\text { de Historia y Sociedad }\end{array}$ & 20 & $\begin{array}{l}\text { El Colegio de } \\
\text { Michoacán }\end{array}$ & 1980 \\
\hline $\begin{array}{l}\text { Estudios de Historia } \\
\text { Moderna y } \\
\text { Contemporánea de } \\
\text { México }\end{array}$ & 17 & UNAM & 1965 \\
\hline Signos Históricos & 8 & UAM-Iztapalapa & 1999 \\
\hline
\end{tabular}

Fuente: Elaborada por los autores, 2021.

En primer lugar, tenemos la revista Historia Mexicana, publicación trimestral adscrita al Centro de Estudios Históricos de El Colegio de México (Colmex) y una de las revistas especializadas en Historia más antiguas en el país, fundada en 1951. Si bien el Colmex ofrece un programa de estudios de doctorado en Historia, no cuenta con una línea de investigación o un seminario institucional específicamente dedicados a la Historia del Presente. Pese a esto, en nuestro conteo es la revista de Historia con más publicaciones que abordan el presente histórico, con un total de 40 artículos. No está de más aclarar que 16 de estos artículos se encuentran en un mismo número, publicado en 2001, el cual fue dedicado a la historia de las principales revistas de Historia del país. El resto de la primera década del 2000 fueron publicados otros 7 artículos. Por su parte, para el siguiente periodo, 2011-2021, encontramos 17. 
Historia y Grafia, fundada en 1993, es la segunda revista histórica con más publicaciones sobre el campo. Esta revista semestral es editada por la Universidad Iberoamericana, institución educativa que presenta un significativo grado de institucionalización de la Historia del Presente. Por un lado, esta subdisciplina forma parte de las líneas de investigación de sus programas académicos de maestría y doctorado. Pero también, desde 2016 dio comienzo el "Seminario Permanente en Historia del Tiempo Presente"6. En términos generales, Historia y Grafía se ha caracterizado por dar un lugar importante a los artículos de carácter teórico e historiográfico -como su propio nombre lo indica-. En este sentido, no es de extrañar que sea la revista en la que se encuentran más textos de carácter teórico sobre cuestiones relacionadas con la Historia del Presente memoria, testimonios, tiempo histórico, regímenes de historicidad, archivos-. En total contabilizamos 38 artículos, 19 para el periodo 2000-2010 e igual número para el 2011-2021.

La tercera revista con más artículos sobre el presente es Secuencia: Revista de Historia y Ciencias Sociales, fundada en 1985. Es una publicación cuatrimestral editada por el Instituto de Investigación Dr. José María Luis Mora, institución pionera en la contratación de historiadores que estudian el presente histórico -ahí trabajan desde hace varios años investigadores como Graciela de Garay y Silvia Dutrénit-7. Además, en sus programas de maestría y doctorado en "Historia Moderna y Contemporánea", la Historia del Tiempo Presente figura como uno de los campos de investigación?. Asimismo, vale resaltar que, en coorganización con la Facultad de Filosofía y Letras de la Universidad Nacional

\footnotetext{
${ }^{6}$ En su perfil, señalan:

"La línea de historia del tiempo presente responde a la necesidad de conocer, analizar y explicar procesos históricos que guardan conexión directa, cuestionamientos o continuidades con el momento actual. Metodológicamente, se vuelven importantes la historia oral, el testimonio, la historia de vida, la comunicación electrónica, los archivos digitales, la literatura, el arte, la performatividad, los elementos fílmicos y hemerográficos a un aparato crítico-heurístico que permita el despliegue de hipótesis y la elaboración de argumentos que funjan como un puente interpretativo entre el pasado inmediato y el presente."

En esta línea participan Rodolfo Gamiño, Laura Ramírez, Ilán Semo, Jane-Dayle Lloyd, Gabriel Poo, Débora Sánchez. Disponible en: https://posgrados.ibero.mx/sites/default/files/202002/Convocatoria Maestria Historia 2020 feb.pdf. Accedido: 30 mayo 2021.

En 2020, ofertaron una nueva plaza en "Historia política y social de México y América Latina, 1960-2020”, que ocupó Mario Virgilio.

Ver la página

web

del

Instituto

Mora:
}

https://www.institutomora.edu.mx/Investigacion/SitePages/Campos-investigacion.aspx

Accedido: 30 mayo 2021. 
Autónoma de México (UNAM), desde 2015 cuenta con el "Seminario Permanente de Historia Contemporánea y del Tiempo Presente en México", coordinado por María del Carmen Collado y Mario Virgilio Santiago Jiménez. En la revista Secuencia contabilizamos un total de 36 artículos, 16 correspondientes al periodo 2000-2010 y 20 para el 2011-2021.

Tzintzun y Relaciones: Estudios de Historia y Sociedad son las siguientes revistas históricas más relevantes en la publicación de contenidos, y las únicas dos, dentro de nuestra lista, que son editadas por instituciones ubicadas fuera de la Ciudad de México. La primera de ellas pertenece al Instituto de Investigaciones Históricas de la Universidad Michoacana de San Nicolás de Hidalgo. Si bien la Historia del Presente no figura entre las líneas de investigación de dicho instituto, ni de sus programas de maestría y doctorado, en la revista Tzintzun se encuentran varios artículos relacionados con ella. Cabe mencionar que la revista da un espacio importante a investigaciones sobre problemas regionales y/o locales, rasgo que resulta de gran importancia para el conocimiento de la realidad nacional, del pasado y del presente. En cuanto a los artículos, contabilizamos un total de 21 relacionados con la Historia del Tiempo Presente, 9 de ellos en el periodo 2000-2010 y 12 para el 2011-2021.

Por su parte, la revista Relaciones fue fundada en 1980 por el historiador michoacano Luis González y González. Es una publicación trimestral editada por el Centro de Estudios Históricos de El Colegio de Michoacán (Colmich). Tanto su programa de doctorado como el Centro de Estudios Históricos cuentan con la línea de investigación “Historia Contemporánea de México y América Latina”, área a la que está adscrita Verónica Oikión Solano, una de las principales representantes de la Historia del Presente mexicano. Relaciones alcanzó un total de 20 artículos sobre esta subdisciplina, 9 para el periodo 2000-2010 y 11 para el 2011-2021.

La revista Estudios de Historia Moderna y Contemporánea de México es una publicación semestral editada por el Instituto de Investigaciones Históricas de la UNAM. Vale decir que esta revista no está registrada en la base de datos Redalyc; sin embargo, consideramos importante incluirla por ser una de las revistas de Historia con mayor antigüedad -1965-, por ser editada por un instituto 
de la principal universidad del país, y porque en su contenido encontramos varios artículos sobre el presente histórico. Si bien es cierto que tanto en el Instituto de Históricas como en sus programas de maestría y doctorado aparece la línea de investigación de "Historia Contemporánea", no cuentan con un seminario institucional sobre el tiempo presente y son mínimos los proyectos de investigación registrados actualmente que rebasan la segunda mitad del siglo XX9 . No obstante, como ya habíamos adelantado, en la revista Estudios de Historia se pueden encontrar publicados 17 artículos sobre el presente histórico mexicano: 8 para el periodo 2000-2010 y 9 para el 2011-2021.

Por último, se ubicó la revista Signos Históricos, de la Universidad Autónoma Metropolitana (UAM), unidad Iztapalapa. Esta revista semestral es editada por una institución que no cuenta con un Departamento de Historia, sino que es el Departamento de Filosofía el que oferta el Doctorado en Humanidades con línea en Historia. Además, hay que señalar que, de las revistas enlistadas, es la de más reciente creación. Si bien Signos Históricos se presenta como una publicación abierta a recibir trabajos de investigación que "analicen temas históricos desde épocas antiguas hasta los que se ubiquen en la historia actual"10, es la que tiene menos artículos sobre el presente histórico. Asimismo, es interesante resaltar que en el periodo 2000-2010 sólo identificamos 2 trabajos de análisis historiográfico- sobre México que rebasan los años 1950 -mientras que sí hay 2 de caso sobre Argentina-. No es sino a partir del 2013 que se encuentran 6 artículos más sobre el presente mexicano.

En síntesis, podemos observar que sólo 3 de las instituciones mencionadas son las que presentan cierto grado de institucionalización de la Historia del Tiempo Presente: el Instituto Mora, la Universidad Iberoamericana y, en menor

\footnotetext{
${ }^{9}$ Dentro del listado de proyecto individuales del 2020 disponible en la página web del instituto sólo hay 3 que abarcan la segunda mitad del siglo XX: "Miradas indígenas sobre el Estado nación. La configuración de comunidades rarámuri durante el ordenamiento ejidal en la Sierra Tarahumara (1952-1992)", de María Isabel Martínez Ramírez; "Claudio Sánchez-Albornoz (18951984): una biografía intelectual”, de Martín Ríos Solama; y "Criminalidad, marginalismo y sociedad (1884-1971)", de Elisa Speckman Guerra. Hay otros tantos proyectos que mencionan el siglo XX, en general, pero son de investigadores que por lo regular trabajan la primera mitad del siglo pasado.

Disponible

en: https://www.historicas.unam.mx/investigacion/proy investigacion/01 Proyectos/ndividuales2020 Web.pdf. Accedido: 30 mayo 2021.

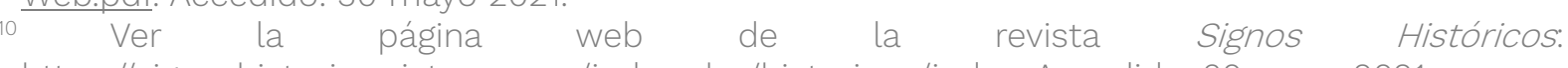
https://signoshistoricos.izt.uam.mx/index.php/historicos/index. Accedido: 30 mayo 2021.
} 
grado, el Colegio de Michoacán. En los 3 casos, sus programas académicos de posgrado cuentan con una línea de investigación sobre Historia del Presente, aunque sólo el Mora y la Ibero utilizan el concepto exacto, mientras que en el Colmich -y podríamos agregar a la UNAM - se trata de "Historia Contemporánea". Lo mismo sucede con las líneas de investigación de cada instituto. Por su parte, sólo el Mora y la Ibero cuentan con un seminario institucional sobre la materia, y ambos fueron creados recientemente. Las revistas editadas por el resto de las instituciones también están abiertas a la publicación de artículos sobre historia reciente. Aunque no sea una diferencia significativa, vale hacer notar que en el periodo de 2011 a 2021 existe un ligero aumento en la publicación de artículos con respecto a la década precedente.

Finalmente, una cuestión que no debemos perder de vista es que los trabajos sobre la Historia del Tiempo Presente no sólo están alojados en las revistas de Historia, sino también en aquellas enfocadas a otras Ciencias Sociales -Ciencia Política, Sociología, Antropología, Educación, Archivo-. Tal como señala Marina Franco (2015, p. 3), la interdisciplinariedad es "un rasgo central del campo que, a la vez, interpela las especificidades y las reticencias de la historiografía para ocuparse de objetos cercanos en el tiempo". En efecto, para tener un panorama más amplio del estado del campo en México, e indagar en torno a una posible agenda de investigación sobre el tiempo presente, en nuestra búsqueda también fue fundamental prestar atención a las revistas especializadas en otras disciplinas de las Ciencias Sociales.

\section{Agendas de investigación}

A partir de la sistematización de la búsqueda -en revistas de Historia y Ciencias Sociales- por referencias directas a la historia reciente o del presente,

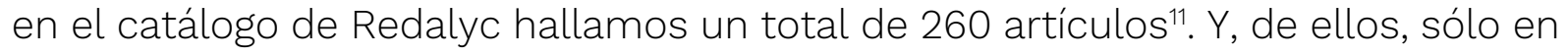
12 hay algún tipo de mención explícita a la Historia del Tiempo Presente, historia inmediata, historia reciente o historia contemporánea. La cifra de artículos

\footnotetext{
${ }^{11}$ Esta cifra contempla los artículos de la revista Estudios de Historia Moderna y Contemporánea de México, del Instituto de Investigaciones Históricas de la UNAM, la cual, como mencionamos en su momento, no está registrada en Redalyc.
} 
publicados en las revistas indexadas nos parece un indicador de que la Historia del Presente no se escribe con nombre propio en México. Esto no quiere decir que no haya avances en su consolidación como parcela historiográfica o que el número refleje la producción global al respecto en México -sólo fue consultada una base de datos académica-. Sin embargo, sí nos habla de una historiografía que aún no tiene un espacio institucionalizado dentro del campo científico del conocimiento en México, y de las estrategias de divulgación - publicación- de los autores para comunicar el avance de sus investigaciones; por ejemplo, muchas veces resulta más fácil publicar en revistas de Ciencias Sociales que de Historia.

Dentro del conjunto de artículos mencionados -12 de 260- se encuentran los trabajos de Verónica Oikión Solano, Massimo Modonesi, Carlos Macías, Margarita Salazar Mendoza, Stephan Scheuzger, Isabel Arcudia García, Francisco Pérez Piñón, Fernando González, Amílcar Carpio, Edoardo Grendi, Diana Guillén, y Eugenia Allier Montaño. Ahora, si bien no fue posible localizar un mayor número de publicaciones con referencias directas al campo de Historia del Presente, identificamos en la búsqueda diversos textos que están relacionados con él. Planteamos en nuestra búsqueda criterios amplios para no constreñir el presente histórico a fechas ni temáticas específicas, mantuvimos una actitud abierta para ser capaces de reconocer su constante definición, que hace posible que sus márgenes sean móviles y con ello evolucione, abarque nuevos temas, desarrolle sus límites y retos metodológicos.

De esta manera, los registros encontrados en la sistematización de la base de datos de Redalyc nos dan pistas acerca de la consolidación de agendas de investigación de esta subdisciplina. En la tabla 2 observamos el número de artículos agrupados en categorías generales -asuntos políticos, sociales, económicos, etc.- y posteriormente explicaremos los subtemas que los conforman a cada una de ellas ${ }^{12}$.

\footnotetext{
12 Si bien muchas de estas publicaciones vienen de revistas especializadas en Sociología y Ciencia Política, fueron incluidas por su tratamiento sobre los temas. Existe en los registros incluidos una perspectiva histórica de reconstruir procesos y cambios en los problemas analizados. Se destacan, entonces, los estudios que intentan ver contextos históricos, orígenes o antecedentes, tiempos fundacionales, entre otros.
} 
Tabla 2 - Temas más relevantes en publicaciones sobre el tiempo presente en México

\begin{tabular}{|ll|}
\hline Temas & Frecuencia \\
\hline 1. Asuntos políticos & 100 \\
\hline 2. Asuntos sociales & 66 \\
\hline 3. Análisis historiográficos & 48 \\
\hline 4. Teoría y metodología & 27 \\
\hline 5. Asuntos culturales & 8 \\
\hline 6. Asuntos económicos & 6 \\
\hline 7. Historia de vida & 5 \\
\hline
\end{tabular}

Fuente: Elaborada por los autores, 2021.

La categoría Asuntos políticos fue la que más artículos agrupó. Privilegiamos aquellos textos en cuyo enfoque analítico priman las relaciones de poder para analizar los procesos históricos. De tal manera, entendemos que lo político es una característica del conflicto, del antagonismo y de las disputas que enfatiza en las subordinaciones que produce el poder que es contestado o resistido de múltiples maneras (MOUFFE, 2007). Entre ellos sobresale un tema de estudio que tiene gran presencia en el país: los movimientos estudiantiles, particularmente el 68 mexicano; se trata de trabajos que abordan al estudiantado como sujeto social y político y los conflictos universitarios en México como eje el movimiento de 1968, la huelga de la UNAM de 1999, la movilización de 2014 por Ayotzinapa-. Dentro de esta temática encontramos, por ejemplo, los aportes de Ariel Rodríguez Kuri (2003), Gilda Waldman (2000), Eugenia Allier Montaño (2009), Ricardo Pozas Horcasitas (2014) y Aquiles Chihu Amparán (2018). Asimismo, las guerrillas y movimientos armados - principalmente el EZLN- fueron un tema recurrente, como los muestran los trabajos de Ángel Escamilla (2017) y Abelardo Hernández (2011).

Un amplio grupo de trabajos de esta categoría son los estudios sobre la violencia. Nos referimos a los análisis que señalan ejercicios o el uso de fuerza física y simbólica para conseguir objetivos específicos: coaccionar, presionar y/o subordinar. Dentro de estos trabajos ubicamos a quienes investigan temas relacionados con la violencia de Estado, que se concentran en el estudio del periodo de los años 1960-1980: autoritarismo, estrategias de contrainsurgencia, 
documentación de delitos de tortura, represión sistemática y espionaje. A manera de ejemplo, podemos destacar los textos de María del Carmen Collado (2011), Verónica Oikión Solano (2011, 2016a, 2016b y 2021) y Luis Sánchez Amaro (2019). Asimismo, incluye aquellos que documentan las consecuencias de estos ejercicios violentos: principalmente la desaparición forzada y el exilio (ROMO, 2015; MENDOZA GARCÍA, 2011). De otra parte, se incluyeron los estudios que abordan la comisión de ejercicios violentos posteriores al 2000 mayoritariamente-: las organizaciones criminales que practican delitos y nuevas consecuencias de estos como las migraciones forzadas por violencia (QUERALES MENDOZA, 2015; OCHOA, 2017).

Como resultado del contexto de los festejos del bicentenario de la Independencia en 2010, las conmemoraciones fueron otro tema que hizo no poca tinta. Textos como los de Carlos Ríos Gordillo (2013), Sebastián Vargas Álvarez (2017) y Luis Fernando Granados (2010) dan cuenta de los eventos, las exposiciones museográficas y las lecturas de la conmemoración en relación con la historiografía del presente. Finalmente, las elecciones presidenciales, la formación y la consolidación de grupos de derecha e izquierda, los procesos de participación ciudadana, las relaciones del periodismo y el poder político, los partidos políticos y sindicatos son otros tantos aspectos que fueron trabajados entre 2000 y 2021.

Dentro de la segunda categoría, Asuntos sociales, la educación tuvo una presencia importante. Marcamos la diferencia entre los movimientos educativos que señalan la militancia o las disputas políticas que enfrentaron, del aspecto educativo entendido como una agenda de investigación que aborda no sólo a los estudiantes, sino posturas más amplias de la docencia, la pedagogía, la ciencia educativa, la escuela, el estatus de la disciplina, entre otros. En la búsqueda hallamos estudios sobre las políticas educativas en México (BUENFIL, 2000); la institucionalización de la educación en México relacionada con los libros de textos, la creación y consolidación de programas educativos y la creación de instituciones educativas (VARGAS-DELGADO; AVELLA-ALAMINOS, 2015; SOSA ÁLVAREZ, 2007); y la enseñanza de la Historia y su relación con los sujetos educativos (GALVÁN LAFARGA, 2002). 
Las cuestiones de género, el feminismo y la homosexualidad forman parte importante dentro de lo social en las agendas de investigación de la Historia del Tiempo Presente, principalmente a partir del 2010: las relaciones entre el patriarcado y la clase social (DZIB CAN, 2015); las reivindicaciones sexuales y los reclamos de justicia económica de las mujeres (FUENTES, 2014); y los espacios de sociabilidad gay (LAGUARDA, 2010) son algunas de ellas. Como podemos observar, el espectro de realidades estudiadas en los últimos años es bastante amplio: encontramos textos que van desde el estudio de los festivales musicales como un medio de protesta encubierta (MORENO ELIZONDO, 2019), pasando por análisis de la relación entre felicidad, lujo y consumo en las clases medias altas de la Ciudad de México (ROSELLÓ SOBERÓN, 2021), hasta las lamentables experiencias de movilidad humana en contexto de violencia sostenida (GÓMEZJOHNSON, 2019). Una última temática que vale destacar dentro de la categoría de lo social es el papel de los medios de comunicación en la vida cotidiana, particularmente la televisión y el internet, dos tecnologías de nuestro presente histórico que, sin duda, han permeado y transformado profundamente nuestra vida cotidiana. Las investigaciones de Laura Camila Ramírez Bonilla $(2015,2016)$ y Amílcar Carpio Pérez (2021) son muy ilustrativas al respecto.

La tercera categoría corresponde a los Análisis historiográficos. En este rubro ubicamos aquellos trabajos que analizan los cambios y permanencias de las formas de narrar el pasado, sus fuentes y metodología de las publicaciones históricas recientes. Dentro de ellas sobresalieron los trabajos dedicados a las revistas académicas. Los procesos de institucionalización de las disciplinas en México han hecho que, principalmente en periodos conmemorativos, se escriban artículos frente a la producción científica publicada en México, los cuales no se editan en las mismas revistas sobre las cuales se escribe (GARCIADIEGO, 2001; GASCÓN MURO, 2005). Es interesante observar que existen intercambios entre estas instituciones y que dialogan en torno a la historia de las revistas, las fechas y conmemoraciones de su publicación, los desafíos y las experiencias de revistas científicas en el país. Pero también encontramos análisis de otras producciones historiográficas como la obrera (CÁRDENAS GARCÍA, 2001), de las guerrillas (ÁVILA CORONEL, 2016) o de la arquitectura (SIFUENTES SOLÍS; ACOSTA COLLAZO, 2014), por sólo mencionar algunos ejemplos. 
En la categoría Teoría y metodología agrupamos los trabajos referentes a los debates propios del campo historiográfico. Estos registros señalan discusiones respecto a un marco común de análisis dentro de esta historia y la creación de una identidad historiográfica. Algunas de las discusiones encontradas en estos registros fueron: las paradojas de la historia contemporánea o la historiografía del siglo XXI (GRENDI, 2003), la relación y distinción entre el pasado, lo reciente y lo inmediato (ANNINO VON DUESK, 2013), el contexto de surgimiento de la Historia del Presente, la función del historiador y la aceleración a la historia (HARTOG, 2003, 2009) y su fuerte vínculo con la memoria y los lugares de memoria (ALLIER MONTAÑO, 2008). También contemplamos dentro de esta categoría aquellos textos que reflexionan en torno al uso de ciertas fuentes que son comunes en la Historia del Presente, tales como la fotografía (DEL CASTILLO TRONCOSO, 2007), o las noticias televisivas (ROMANO, 2002). Asimismo, se encuentran valiosos trabajos que reflexionan sobre los archivos -públicos o privados, físicos o digitales- y las discusiones respecto al almacenamiento de la historia. Por sólo mencionar algunos de ellos, contamos con los textos de Pablo Yankelevich y Paola Chenillo (2008), Isabel Galina Russell (2020) y Martha Rodríguez García (2008).

Como hemos señalado en otro espacio, "pese a la importancia creciente de la historia del presente, son pocos los trabajos teóricos dedicados a esta historia" y los trabajos acerca de ésta privilegian los límites del campo "temáticas, las dificultades y los retos de la historia del presente, pero siempre con una visión de este campo como periodo histórico y no como forma de historizar" (ALLIER MONTAÑO, 2018, p.103). México sigue tal tendencia: la Historia del Tiempo Presente es tratada a partir de su delineamiento historiográfico, pero no en su especificidad nacional.

Las últimas 3 categorías - Asuntos culturales, Asuntos económicos e Historia de vida- han sido las menos trabajadas, pero esto no quita que sean aspectos que también conciernen a nuestro presente, y hay diversos investigadores que se están ocupando de ellos. Artículos como los de Eli Bartra y John Mraz (2006), Jorge Alejandro Cruz Domínguez (2017) y Angélica Morales Figueroa y Patricia Pérez Munguía (2020) dan cuenta de algunas manifestaciones 
culturales como el cine, el muralismo y el patrimonio. Por su parte, Javier Moreno Lázaro (2009), Aurora Gómez Galvarriato (2020) y Lylia Palacios Hernández (2008) abordan cuestiones de índole económica, como la formación de la empresa galletera en México, el papel del Banco de México en el desarrollo industrial del país a mediados del siglo XX O las fallidas estrategias empresariales de integración en el contexto de la globalización.

A partir de la revisión de las agendas o temas de investigación vemos que los estudios de Historia del Presente en México acentúan la escala nacional y pocas investigaciones versan acerca del estudio del presente en escalas transnacionales o comparativas. Por estar inmerso en un campo científico consolidado, esta subdisciplina reproduce disputas sociales y políticas, atestigua los cambios en la significación del presente y puede volver parte de su estudio a lo que es señalado como ilegítimamente histórico, abonando así a restablecer los límites del conocimiento científico producido desde la historia y dando reconocimiento a las demandas sociales. El tema de la violencia parece ser un buen ejemplo en México: en los registros fue posible observar que es una preocupación de los historiadores del presente y que sus estudios analizan su especificidad y transformación -de violencia de Estado y violencia política, a violencia criminal y feminicida, por ejemplo-.

Finalmente, la revisión de las revistas científicas también nos permitió observar el carácter centralista en la producción académica y la formación histórica en México. Como ya mencionamos anteriormente, para el caso de las revistas de Historia sólo 2 de 7 eran regionales y las 2 del estado de Michoacán. Sin embargo, si miramos las 25 revistas con mayor publicación de contenidos de Historia del Presente, la tendencia se mantiene: el 20\% es regional (Figura 1). Además, de las revistas editadas en el aérea metropolitana y en la Ciudad de México, el 30\% se concentra en diferentes instituciones de la UNAM: 3 revistas son editadas por la Facultad de Ciencias Políticas y Sociales, 1 por el Instituto de Investigaciones Jurídicas y 1 por el Instituto de Investigaciones sobre la Universidad y la Educación. La alta concentración en el centro del país llama a la Historia del Tiempo Presente para cuestionar las afirmaciones nacionales y sacar provecho de los estudios regionales para pensar nuevas periodizaciones, estudiar los impactos y temas relevantes del presente mexicano. 
Figura 1 - Ubicación de las instituciones que editan revistas especializadas con contenidos sobre el tiempo presente en México

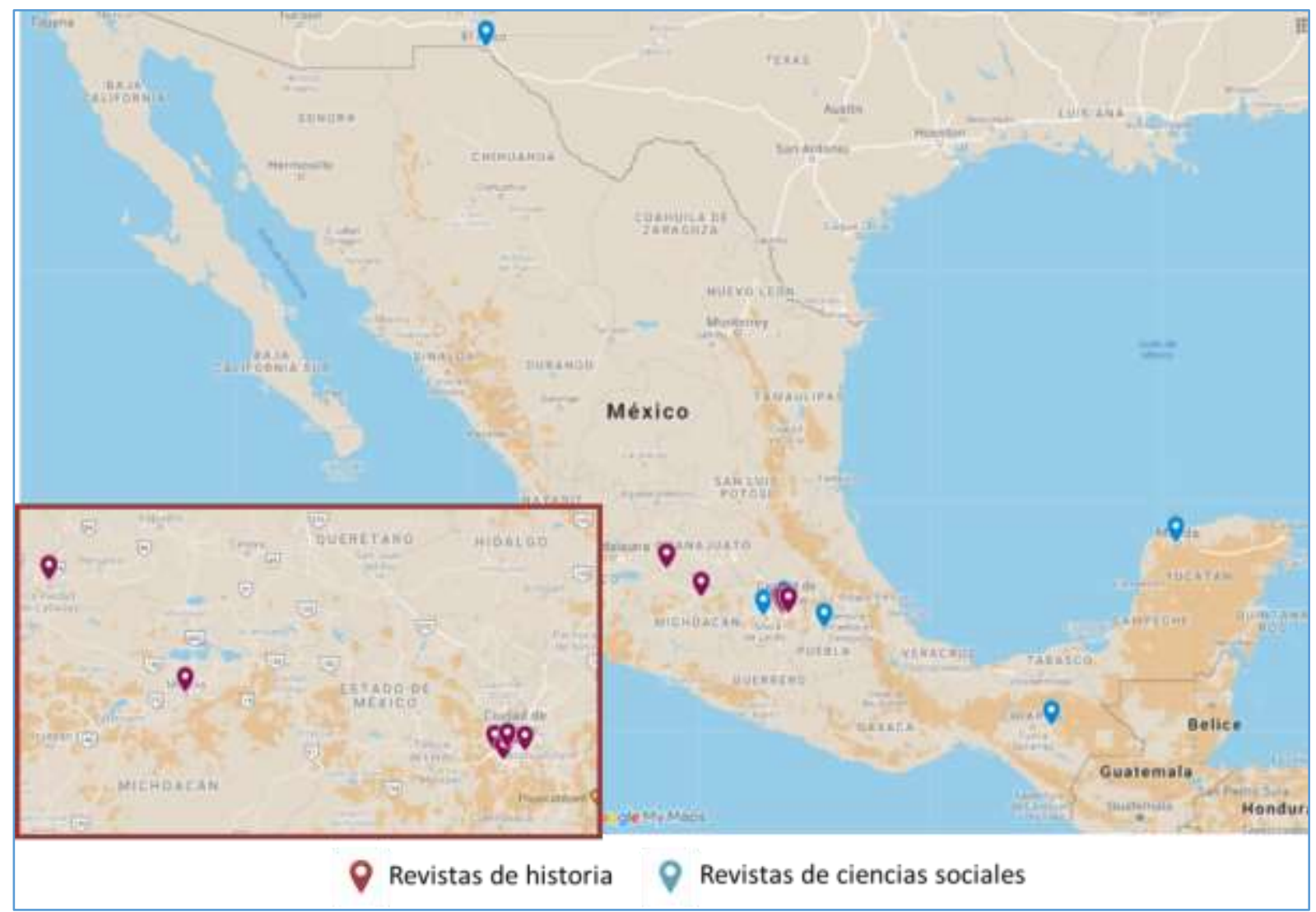

Fuente: Elaborada por los autores, 2021.

\section{Instituciones y estratos generacionales del campo}

Como dijimos en un principio, en México han existido casi siempre historiadores e historiadoras interesadas en el presente histórico. Sin embargo, muchas veces se trató de casos aislados. Dentro de la generación nacida a finales de la década de 1940 y los años 1950, y socializados en las décadas de 1960 y 1970, existen casos aislados, pero relevantes, como Pablo Yankelevich, Graciela de Garay, Silvia Dutrénit, Ilán Semo, Fernando González, Gloria Tirado Villegas, Lorenzo Meyer, Sergio Aguayo. Si bien en algunos de ellos hay un componente biográfico importante al elegir el tema, todos lo hacen desde una aproximación historiográfica y objetiva. Algunos como Pablo Yankelevich y Silvia Dutrénit han dedicado parte importante de sus investigaciones a la historia del exilio sudamericano en México, por ejemplo. Otros más jóvenes como Verónica Oikión, Ariel Rodríguez Kuri y Alberto del Castillo han incursionado en el movimiento 
estudiantil de 1968 y en los movimientos armados. Y si bien su labor es imprescindible al comprender el campo de la Historia del Presente en el país, en general estos esfuerzos no generaron un campo de debate y discusión.

No sería sino hasta principios de la década de 2010 que una nueva generación de historiadores e historiadoras estaría interesada no sólo en las temáticas sino en el debate y el intercambio que permite un campo. Entre ellos hay que mencionar a Camilo Vicente Ovalle, César Iván Vilchis Ortega, Rodolfo Gamiño, Alicia de los Ríos, Sergio Arturo Sánchez Parra, Aleida García Aguirre, Yllich Escamilla, Rigoberto Reyes, Rubén Ortiz, Francisco Ávila Coronel, Mario Virgilio Santiago, Denisse Cejudo, César Valdez, Halina Gutiérrez Mariscal y Magdalena Pérez Alfaro.

Fue a partir de varios de ellos que comenzó la construcción de un campo. En 2012, César Iván Vilchis Ortega, Camilo Vicente Ovalle y Eugenia Allier Montaño constituyeron el Seminario Institucional de Historia del Tiempo Presente que, conformado en el Instituto de Investigaciones Sociales de la UNAM y con su respaldo, pudo a la vez tener un espacio cerrado -para la discusión y definición de la subdisciplina- y uno abierto al público que buscaba generar debates y reflexiones entre especialistas. De esa manera, en 2013 se llevó a cabo el coloquio "Para una Historia del Presente en México", con una convocatoria abierta y el interés por conocer el estado de las investigaciones sobre Historia del Presente en el país: el balance fue que el campo todavía era muy incipiente. En 2015 se realizó el seminario “A 50 Años del Asalto al Cuartel Madera”. Finalmente, en 2017 se llevó a cabo el Taller “El Presente, Tiempo Histórico" para debatir los postulados teórico-metodológicos de esta parcela historiográfica. Respecto a los debates y definiciones teóricos: las temporalidades, temáticas, aspectos sociopolíticos, el concepto que debería utilizarse para referirse a este tipo de historiografía. Por otro lado, la cuestión de las fuentes y las metodologías empleadas en esta parcela historiográfica: tanto la especificidad como la novedad de algunas de las fuentes, así como los métodos para su tratamiento e interpretación. Por último, para intentar un balance del campo: la construcción de los distintos campos nacionales y regionales, las temáticas abordadas y los balances historiográficos. Resultado de estos debates fue el libro En la cresta de 
la ola. Debates y definiciones en torno a la historia del tiempo presente, coordinado por Eugenia Allier Montaño, César Iván Vilchis Ortega y Camilo Vicente Ovalle (2020).

En años recientes, el campo ha emprendido un fuerte crecimiento.

En primer lugar, se han conformado varios grupos y seminarios que reivindican a la Historia del Presente como su campo disciplinar: en la Universidad Iberoamericana existe el Seminario Permanente Historia del Tiempo Presente, que en febrero de 2016 realizó el Coloquio "Para pensar la Historia del Tiempo Presente", con una convocatoria abierta, en donde se presentaron 10 conferencias magistrales y más de 40 ponencias nacionales e internacionales, mostrando el crecimiento del campo en poco tiempo. También está el Seminario Permanente de Historia Contemporánea y del Tiempo Presente de México, que une a académicos del Instituto Mora y de la Facultad de Filosofía y Letras de la UNAM que, en agosto de 2017, convocó al "I Coloquio de Doctorantes en Historia, Siglos XX-XXI, de la Posrevolución al Presente". Igualmente, en enero de 2020, se constituyó el Seminario Interinstitucional de Historia del Tiempo Presente, grupo de trabajo en el que se unen esfuerzos de la Dirección de Estudios Históricos del Instituto Nacional de Antropología e Historia, del Instituto Nacional de Estudios Históricos de las Revoluciones en México y del Instituto de Investigaciones Sociales de la UNAM.

En segundo lugar, muchas universidades que habían sido reacias a aceptar la Historia del Presente han comenzado a abrir plazas centradas en esta parcela historiográfica: el Colmex, el Instituto Mora e incluso el Instituto de Investigaciones Históricas de la UNAM, que, entre sus líneas de investigación, no contempla la segunda mitad del siglo XX.

\section{Cerrando lo que comienza a abrirse}

Tratar de promover la creación de un campo no es ocioso. No se trata de institucionalizar el campo o de obtener recursos para la investigación. Lo más importante de que existan redes es la posibilidad de discutir los trabajos empíricos y teóricos con pares que conocen el tema y pueden ayudar a pensar 
en voz alta. El trabajo colectivo siempre es mucho más rico que el individual. Además, de esa forma existe la posibilidad de debatir los presupuestos teóricos, epistemológicos y metodológicos de una historia en construcción.

En este artículo, hemos realizado una primera tentativa, incipiente, de balance de la Historia del Tiempo Presente en México. Hemos podido observar que en este país se hace una Historia del Presente "a la mexicana", con características propias debidas tanto a las circunstancias políticas, sociales e históricas del país, como a los intereses de sus historiadores: no se trata de un periodo específico, sino de una historia en movimiento que estudia desde los años 1950 hasta la actualidad de diferentes maneras, y que aborda temáticas que no sólo se refieren a la violencia y los movimientos sociales, cuestiones de "dolor" y "trauma”, como ocurre en otros países del área13.

Un campo se constituye de diferentes maneras. La redacción y publicación de trabajos de licenciatura y doctorado, de artículos de investigación y de libros es muy importante. Que existan revistas dispuestas a publicar es fundamental. No obstante, a ello debe sumarse la existencia de seminarios -abiertos y cerrados-, en donde puedan discutirse la temática, las definiciones de la especialidad y las cuestiones metodológicas. Coloquios, talleres y seminarios de algunos días en donde se debatan y presenten los avances de investigación son también imprescindibles. Todo eso muestra el interés de sectores importantes cualitativa y cuantitativamente- por conformar un campo historiográfico. Cuando ello se ha cumplido existe un campo, en construcción o ya consolidado. Pero no es finalmente sino cuando se crean plazas en universidades y centros de investigación, cuando hay revistas especializadas en el tema, y cuando este campo es reconocido en las burocracias universitarias, cuando se puede decir que el campo está institucionalizado ${ }^{14}$.

\footnotetext{
${ }^{13}$ Creemos que uno de los retos es que la Historia del Presente, realizada en México, no se centre exclusivamente en este país. La historia contemporánea debe tener también una perspectiva global. No se puede dejar de mirar lo que se está haciendo en Argentina, EE. UU., Canadá, España, Francia o Alemania.

${ }^{14}$ Otro punto importante en ese sentido es el reconocimiento y la necesidad que puede existir en el campo político-social. Es decir, el requerimiento de historiadores e historiadoras para resolver cuestiones de carácter político o social, como en juicios penales, comisiones de verdad, en materia de legislación, de investigaciones sobre derechos humanos. Algo que en México está comenzando a ocurrir. Ver Eugenia Allier Montaño (2020).
} 
Como hemos delineado en las páginas anteriores, en México ya se han ido cumpliendo los pasos anteriores. Existe ya un campo, no sólo en construcción, sino que se está consolidando y, aún más, institucionalizando. Un campo que está teniendo un rápido crecimiento, al que valdrá la pena seguirle la pista en los próximos años.

\section{Referencias}

AGUAYO, Sergio. De Tlatelolco a Ayotzinapa: las violencias del Estado. México: Editorial Ink, 2015.

AGUAYO, Sergio. El activismo civil en la transición mexicana a la democracia. In: BIZBERG, Ilán; MEYER, Lorenzo (eds.). Una historia contemporánea de México: tomo 3: las instituciones. México: Océano, 2009. p. 291-346.

AGUAYO, Sergio; TREVIÑO, R. Javier. Fox y el pasado: la anatomía de una capitulación. Foro internacional, Ciudad de México, v. 47, n. 4, p. 709-739, oct./dic. 2007.

ALLIER MONTAÑO, Eugenia; VICENTE OVALLE, Camilo; GRANADA Juan Sebastián. Recasting history to cast off shadows: state violence in Mexico, 19602018. In: MANDOLESSI, Silvana; OLALDE RICO, Katia (eds.). Disappearances in Mexico: from the "Dirty War" to the "War on Drugs. Londres: Routledge, [2022]. No prelo.

ALLIER MONTAÑO, Eugenia; VILCHIS ORTEGA César; VICENTE OVALLE, Camilo. En la cresta de la ola: debates y definiciones en torno a la historia del tiempo presente. México: Universidad Nacional Autónoma de México-Instituto de Investigaciones Sociales: Bonilla Editores, 2020.

ALLIER MONTAÑO, Eugenia; CRENZEL, Emilio (coords.). Las luchas por la memoria en América Latina: historia reciente y violencia política. México: Bonilla Artigas Editores: IISUNAM, 2015.

ALLIER MONTAÑO, Eugenia. 68, el movimiento que triunfó en el futuro: historias, memorias y presente. México: Instituto de Investigaciones Sociales de la Universidad Nacional Autónoma de México: Bonilla Editores, 2021.

ALLIER MONTAÑO, Eugenia. Ética y política en el historiador del tiempo presente. In: ALLIER MONTAÑO, Eugenia; VILCHIS ORTEGA, César Iván; VICENTE OVALLE, Camilo (eds.). En la cresta de la ola: debates y definiciones en torno a la historia del tiempo presente. México: Universidad Nacional Autónoma de México-Instituto de Investigaciones Sociales/Bonilla Editores, 2020. p. 175-194. 
ALLIER MONTAÑO, Eugenia. Balance de la historia del tiempo presente: creación y consolidación de un campo historiográfico. Revista de Estudios Sociales, Bogotá, n. 65, p. 100-112, jul. 2018.

ALLIER MONTAÑO, Eugenia. Los lieux de mémoire: una propuesta historiográfica para el análisis de la memoria. Historia y Grafía, Ciudad de México, n. 31, p. 165 192, 2008.

ALLIER MONTAÑO, Eugenia. Presentes-pasados del 68 mexicano: una historización de las memorias públicas del movimiento estudiantil, 1968-2007. Revista Mexicana de Sociología, Ciudad de México, v. 71, n. 2, p. 287-317, abr./jun. 2003.

ÁLVAREZ ICAZA, Emilio. La institucionalización de los derechos humanos. Reflexiones en torno a la sociedad civil y los organismos públicos de derechos humanos. In: BLANCARTE, Roberto (coord.). Los grandes problemas de México: culturas e identidades: tomo XVI. México: Colmex, 2010. p. 115-148.

ANNINO VON DUESK, Antonio. La historia frente a los tiempos de la dispersión. Tzintzun. Revista de Estudios Históricos, Morelia, n. 58, p. 181-199, jul./dic. 2013.

ARÓSTEGUI, Julio. La historia vivida: sobre la historia del presente. Madrid: Alianza Editorial, 2004.

ÁVILA CORONEL, Francisco. Historiografía de la guerrilla del Partido de los Pobres (PDLP) (Atoyac, Guerrero). Secuencia, Ciudad de México, n. 95, p. 152-187, may./ago. 2016.

BARTRA, Eli; MRAZ, John. Las dos Fridas: historia e identidades transculturales. Secuencia, Ciudad de México, n. 65, p. 137-164, mayo/ago. 2006.

BLOCH, Marc. Apologie pour l'histoire ou Métier d'historien. Edición anotada por Étienne Bloch. París: Armand Colin, 1997.

BUENFIL, Rosa Nidia. Globalización y políticas educativas en México 1988-1994: encuentro de lo universal y lo particular. Revista Latinoamericana de Estudios Educativos (México), Ciudad de México, v. 30, n. 3, p. 55-92, 2000.

BURKE, Peter (ed.). Formas de hacer historia. Madrid: Alianza Editorial, 2003.

DZIB CAN, Ubaldo. Patriarcado y clase social: cambios y permanencias en las relaciones de género, generaciones y clase en el suroeste rural de Campeche, 1940-2010. Relaciones. Estudios de historia y sociedad, Zamora, v. 36, n. 143, p. 233-278, sept. 2015.

CALANDRA, Benedetta. "It Is Not a Part of American History That We Are Proud of" Declassification Projects in the United States (1993-2002). In: ALLIER, Eugenia; CRENZEL, Emilio (cords.). The Struggle for Memory in Latin America. New York: Palgrave Macmillan, 2015. p. 203-221. 
CANSINO ORTIZ, César. La transición mexicana, 1977-2000. México: CEPCOM, 2000.

CÁRDENAS GARCÍA, Nicolás. La historiografía obrera en México (1972-1991).

Política y Cultura, Ciudad de México, n. 16, p. 35-66, 2001.

CARPIO PEREZ, Amílcar. Los bulos en tiempos de influenza: la transmisión de rumores en internet durante la epidemia en México de 2009. Signos Históricos, Ciudad de México, v. 23, n. 45, p. 272-315, enero/jun. 2021.

CHIHU AMPARÁN, Aquiles. Frames del discurso público en la arena política del 68. Polis, Ciudad de México, v. 14, n. 1, p. 81-105, 2018.

COLLADO, María del Carmen. Autoritarismo en tiempos de crisis: Miguel de la Madrid 1982-1988. Historia y Grafía, Ciudad de México, n. 37, p. 149-177, dic. 2011.

CRUZ DOMINGUEZ, Jorge Alejandro. La visión revolucionaria de Arnold Belkin: México y Nicaragua ante sus íconos. Tzintzun. Revista de Estudios Históricos, Morelia, n. 66, p. 169-205, jul./dic. 2017.

CUESTA BUSTILLO, Josefina. Historia del presente. Salamanca: Ediciones de la Universidad Complutense, 1993.

DELACROIX, Christian. Entre doutes et renouvellements, les années 1980-2000. In: DELACROIX, Christian; DOSSE, Francois; GARCÍA, Patrick (coords.). Les courants historiques en France, XIXe-XXe siecle. France: Armand Colín, 2007, p. 483-634.

DEL CASTILLO TRONCOSO, Alberto. La frontera imaginaria: usos y manipulaciones de la fotografía en la investigación histórica en México. Cuicuilco, Ciudad de México, v. 14, n. 41, p. 193-215, 2007.

ESCAMILLA, Ángel. Estructura social y organizativa de la Liga Comunista 23 de Septiembre: 1973-1980. Signos históricos, Ciudad de México, v. 19, n. 38, p. 172195, dic. 2017.

FAZIO, Hugo. La historia del tiempo presente: historiografía, problemas y métodos. Bogotá: Universidad de los Andes, 2010.

FRANCO, Marina; LEVÍN Florencia (comps.). Historia reciente: perspectivas y desafíos para un campo en construcción. Buenos Aires: Paidós, 2007.

FRANCO, Marina. La teoría de los dos demonios en la primera etapa de la posdictadura. In: FRANCO, Marina; FELD, Claudia (coords). Democracia, hora cero: actores políticas y debates en los inicios de la posdictadura. Buenos Aires: Fondo de Cultura Económica, 2015. p. 23-80.

FUENTES, Pamela. Entre reivindicaciones sexuales y reclamos de justicia económica: divisiones políticas e ideológicas durante la Conferencia Mundial del Año Internacional de la Mujer. México, 1975. Secuencia, Ciudad de México, n. 89, p. 163-192, mayo/ago. 2014. 
GALINA RUSSELL, Isabel et al. Hemeroteca digital nacional de México, su historia y alcance como fuente para proyectos digitales. Relaciones. Estudios de historia y sociedad, Zamora, v. 41, n. 163, p. 200-219, 2020.

GALVÁN LAFARGA, Luz Elena. Historia de la educación. Revista Mexicana de Investigación Educativa, Ciudad de México, v. 7, n. 15, p-217-221, mayo/ago. 2002.

GARAY, Graciela de (coord.). Para pensar el tiempo presente: aproximaciones teórico-metodológicas y experiencias empíricas. México: Instituto Mora, 2007.

GARCIADIEGO, Javier. Revistas revisitadas: ventana a la historiografía mexicana del siglo XX. Historia Mexicana, Ciudad de México, v. 51, n. 2, p. 221-231, oct./dic. 2001.

GARTON ASH, Timothy. History of the present : essays, sketches and despaches from Europe in the 1990s. Londres: Penguin Book, 1999.

GASCÓN MURO, Patricia et al. Historias y experiencias compartidas por las revistas de la UAM. Reencuentro. Análisis de Problemas Universitarios, Ciudad de México, n. 42, p. 7-12, 2005.

GÓMEZ GALVARRIATO, Aurora. La construcción del milagro mexicano: el Instituto Mexicano de Investigaciones Tecnológicas, el Banco de México, y la Armour Research Foundation. Historia Mexicana, Ciudad de México, v. 69, n. 3, p. 1247-1309, enero/mar. 2020.

GÓMEZ-JOHNSON, Cristina. Huir para no morir: movilidad humana en contexto de violencia sostenida. El caso mexicano. Historia y Grafía, Ciudad de México, n. 52, p. 57-95, enero/jun. 2019.

GRANADOS, Luis Fernando. Independencia sin insurgentes. El bicentenario y la historiografía de nuestros días. Desacatos, Ciudad de México, n. 34, p. 11-26, sept./dic. 2010.

GRENDI, Edoardo. Paradojas de la historia contemporánea. Relaciones. Estudios de historia y sociedad, Zamora, v. 24, n. 95, p. 267-278, 2003.

HARTOG, François. Historia, memoria y crisis del tiempo: ¿qué papel juega el historiador? Historia y Grafía, Ciudad de México, n. 33, p. 115-131, 2009.

HARTOG, François. Órdenes del tiempo, regímenes de historicidad. Historia y Grafía, Ciudad de México, n. 21, p. 73-102, 2003.

HERNÁNDEZ, Abelardo. El EZLN, los partidos políticos y los procesos electorales. Espacios Públicos, Toluca, v. 14, n. 31, p. 119-135, mayo/ago. 2011.

INSTITUT D'HISTOIRE DU TEMPS PRÉSENT [IHTP]. Ecrire l'histoire du temps présent. París: CNRS, 2003. 
LABASTIDA MARTÍN DEL CAMPO, Julio; LÓPEZ LEYVA, Miguel Armando. México: una transición prolongada (1988-1996/97). Revista Mexicana de Sociología, Ciudad de México, v. 66, n. 4, p. 749-806, oct./dic. 2004.

LAGUARDA, Rodrigo. El ambiente: espacios de sociabilidad gay en la ciudad de México, 1968-1982. Secuencia, Ciudad de México, n. 78, p. 149-174, sept./dic. 2010.

LOAEZA, Soledad. México, 1968: Los orígenes de la transición. In: SEMO, Ilan (coord.) La transición interrumpida: México 1968-1988. México: Universidad Iberoamericana: Nueva Imagen, 1993. p. 15-48.

MENDOZA GARCíA, Jorge. La tortura en el marco de la guerra sucia en México: un ejercicio de memoria colectiva. Polis, Ciudad de México, v. 7, n. 2, p. 139-179, 2011.

MEYER, Lorenzo. Nuestra tragedia persistente: la democracia autoritaria en México. México: Debate, 2013.

MORALES FIGUEROA, Angélica Navidad; PÉREZ MUNGUÍA, J. Patricia. Dilemas en torno a los procesos de patrimonialización en la región P’urhépecha: un recorrido entre los siglos XIX al XXI. Tzintzun. Revista de Estudios Históricos, Morelia, n. 72, p. 189-213, jul./dic. 2020.

MORENO ELIZONDO, J. Rodrigo. Contracultura e izquierda estudiantil: festivales musicales y protesta encubierta en México: Avándaro y Monterrey, 1971.

Secuencia, Ciudad de México, n. 105, e1594, sept./dic. 2019.

MORENO LÁZARO, Javier. La formación de la gran empresa galletera mexicana, 1907-2007. Historia Mexicana, Ciudad de México, v. 58, n. 3, p. 1045-1092, enero/mar. 2009.

MODONESI, Massimo. Historia, memoria y política: entrevista con Enzo Traverso. Andamios, Ciudad de México, v. 4, n. 8, p. 245-256, 2008.

MONTEMAYOR, Carlos. La violencia de Estado en México: antes y después de 1968. Ciudad de México: Random House, 2010.

MOUFFE, Chantal. En torno a lo político. Buenos Aires: Fondo de cultura económica, 2007.

OCHOA, Marisol. Del crimen organizado al crimen desordenado: una apuesta por la observación conceptual y contextual. Desacatos, Ciudad de México, n. 54, p. 92-105, 2017.

OIKIÓN SOLANO, Verónica. De fosas, exterminio e impunidad en Michoacán: una reflexión desde la historia reciente. Historia y Grafía, Ciudad de México, n. 56, p. 89-128, enero/jun. 2021. 
OIKIÓN SOLANO, Verónica. Dilucidar el laberinto de la desmemoria en la historia reciente: la comisión de la verdad del estado de Guerrero. Cuicuilco, Ciudad de México, v. 23, n. 65, p. 41-69, $2016 a$.

OIKIÓN SOLANO, Verónica. El estado mexicano frente a los levantamientos armados en Guerrero: el caso del Plan Telaraña. Tzintzun. Revista de Estudios Históricos, Morelia, n. 45, p. 65-82, 7 sep. 2016b.

OIKIÓN SOLANO, Verónica. Represión y tortura en México en la década de 1970: un testimonio político. Historia y Grafía, Ciudad de México, n. 37, p. 115-148, 2011.

POZAS HORCASITAS, Ricardo. Los 68: encuentro de muchas historias y culminación de muchas batallas. Perfiles latinoamericanos, Ciudad de México, v. 22, n. 43, p. 19-54, 2014.

QUERALES MENDOZA, May-ek. Exilios contemporáneos: la experiencia reciente desde el valle de Juárez. El Cotidiano, Ciudad de México, n. 191, p. 61-67, 2015.

PALACIOS HERNÁNDEZ, Lylia. Estrategias empresariales de integración fallidas o el difícil tránsito del proteccionismo a la competencia abierta: CYDSA (19452005). Secuencia, Ciudad de México, n. 72, p. 83-110, dic. 2008

RAMIREZ BONILLA, Laura Camila. ¿Qué niño se resiste a la tele? Moralidad y prácticas de los infantes ante el surgimiento de la televisión en la ciudad de México (1950-1962). Trashumante. Revista Americana de Historia Social, Medellín-Ciudad de México, n. 8, p. 226-252, jul./dic. 2016.

RAMIREZ BONILLA, Laura Camila. La hora de la TV: incursión de la televisión y la telenovela en la vida cotidiana de la ciudad de México (1958-1966). Historia Mexicana, Ciudad de México, v. 65, n. 1, p. 289-356, jul./sept. 2015.

RÍOS GORDILLO, Carlos Alberto. La memoria asediada: la disputa por el presente en la conmemoración del bicentenario. Secuencia, Ciudad de México, n. 87, p. 177-204, 2013.

RODRÍGUEZ GARCÍA, Martha. El Archivo General del Estado de Coahuila y la transparencia "En defensa de nuestra memoria". Desacatos, Ciudad de México, n. 26, p. 137-142, enero/abr. 2008.

RODRÍGUEZ KURI, A. Los primeros días. Una explicación de los orígenes inmediatos del movimiento estudiantil de 1968. Historia Mexicana, Ciudad de México, v. 53, n. 1, p. 179-228, 2003.

ROMANO, Renee; POTTER, Clair. 2012. Introduction. Just over our Shoulder. In: POTTER, Claire B.; ROMANO, Renee C. Doing recent history: on privacy, copyright, video games, institutional review boards, activist scholarship, and history that talks back. Georgia: University of Georgia Press, 2012. p. 1-22.

ROMANO, Silvia. Las noticias televisivas como fuentes de la historia. Historia y Grafía, Ciudad de México, n. 18, p. 99-120, 2002. 
ROMO, Rosa Martha. Argentinos en México: procesos de exilio e innovación universitaria/Argentines in Mexico: exile and university innovation processes. RIDE Revista Iberoamericana para la Investigación y el Desarrollo Educativo, Mexicali, v. 5, n. 10, p. 418-432, 2015.

ROSELLÓ SOBERÓN, Estela. Happiness made in Mexico: lujo, consumo y felicidad entre las clases medias altas de las Lomas de Chapultepec (ciudad de México, 2018). Relaciones. Estudios de Historia y Sociedad, Zamora, v. 41, n. 163, p. 1-33, mayo 2021.

ROUSSO, Henry. La dernière catástrofe: l'histoire, le présent, le contemporain. Paris: Gallimard, 2013.

ROUSSO, Henry. Présentation. In: BEDARIDA, François. Histoire, critique et responsabilité. Bruxelles: Complexe: IHTP, 2003.

SALAZAR, Luis (ed.). México 2000: alternancia y transición a la democracia. Ciudad de México: Cal y Arena, 2001.

SALAZAR MENDOZA, Margarita. La literatura juarense: entre el realismo y la historia reciente. Nóesis: Revista de Ciencias Sociales y Humanidades, Ciudad Juárez, v. 23, n. 46, p. 360-387, 2014.

SANCHEZ AMARO, Luis. El espionaje al movimiento estudiantil Nicolaita: los documentos de la DGIPS, 1967-1977. Tzintzun. Revista de Estudios Históricos, Morelia, n. 69, p. 291-316, enero/jun. 2019.

SCHEUZGER, Stephan. La historia contemporánea de México y la historia global: reflexiones acerca de los "sesenta globales". Historia mexicana, Ciudad de México, v. 68, n. 1, p. 313-358, 2018.

SIFUENTES SOLÍS, Manuel Alejandro; ACOSTA COLLAZO, Alejandro.

Aproximación a la reciente historiografía mexicana de arquitectura. Historia Mexicana, Ciudad de México, v. 64, n. 1, p. 291-349, jul./sept. 2014.

SOSA ÁLVAREZ, Ignacio. De la memoria a la historia: los estudios latinoamericanos como disciplina y como comunidad. Revista de la Educación Superior, Ciudad de México, v. 36, n.144, p. 57-85, 2007.

SOMUANO, María Fernanda. Las organizaciones civiles: formación y cambio. In: LOAEZA, Soledad; PRUD-HOMME, Jean-Francois (coords.). Los grandes problemas de México: tomo XIV: Instituciones y procesos políticos. México: FCE, 2010. p. 197-230.

VARGAS-DELGADO, Claudia-Priscila; AVELLA-ALAMINOS, Isabel. El plan de estudios de la licenciatura en Historia del sistema abierto de la UNAM. Una perspectiva histórica. Revista Iberoamericana de Educación Superior, Ciudad de México, v. 6, n. 16, p. 68-88, 2015.

VARGAS ÁLVAREZ, Sebastián. Museografías de la nación: la historia exhibida en México 200 años: la patria en construcción/Museographies of the nation: the 
history displayed in México 200 años: la patria en construcción. Historia y Grafía, Ciudad de México, n. 49, p. 213-244, 2017.

VICENTE OVALLE, Camilo. Archivo y las huellas del presente. In: ALLIER MONTAÑO, Eugenia; VILCHIS ORTEGA, César; VICENTE OVALLE, Camilo (coords.). La cresta de la ola: debates y definiciones en torno a la historia del tiempo presente. México: Universidad Nacional Autónoma de México-Instituto de Investigaciones Sociales: Bonilla Artigas Editores, 2020. p. 297-313.

VICENTE OVALLE, Camilo. Tiempo suspendido: una historia de la desaparición forzada en México, 1940-1980. México: Bonilla Artigas Editores, 2019.

WALDMAN, Gilda. Los movimientos estudiantiles de 1968 y 1999: contextos históricos y reflexiones críticas. Revista Mexicana de Ciencias Políticas y Sociales, Ciudad de México, v. 44, n. 178, p. 277-293, 2000.

WOLDENBERG, José. Transición a la mexicana: lo electoral como eje del cambio político. In: HÉMOND, Aline.; RECONDO, David. (coords.). Dilemas de la Democracia en México. Los Actores Sociales ante la Representación Política. México: IFE: Centro Francés de Estudios Mexicanos y Centroamericanos, 2002. p. 17-27.

YANKELEVICH, Pablo; CHENILLO ALAZRAKI, Paola. El archivo histórico del Instituto Nacional de Migración. Desacatos, Ciudad de México, n. 26, p. 25-42, 2008.

Universidade do Estado de Santa Catarina - UDESC

Programa de Pós-Graduação em História - PPGH Revista Tempo e Argumento Número Especial - 2021 tempoeargumento.faed@udesc.br 